\title{
THE RESEARCH OF PROACTIVE COPING BEHAVIOR OF PATIENTS WITH CHRONIC NON-SPECIFIC LUNG DISEASE
}

\author{
Natalya A. Sirota, \\ Marija A. Yaroslavskaya \\ Moscow State University of Medicine and Dentistry \\ Moscow
}

\begin{abstract}
The purpose of the research was to study the patterns of using proactive coping and adherences to it's different types in patients with chronic non-specific lung diseases. Participants of the study $(\mathrm{N}=180)$ were 30 to 60 years old. The Proactive Coping Inventory was used to assess the patients' psychological status. According to the results of the study patients with chronic non-specific lung diseases use different types of proactive coping behavior while solving problematic and stressful situations. The research revealed that patients with bronchial asthma don't have the skills of independent decision making, definition of objectives, considering of options in solving conflicts or other inconvenient situations sufficiently developed. Patients with chronic obstructive pulmonary disease are less satisfied with the emotional support that they receive from their relatives and closest people, it's harder for them to reveal their feelings and emotions than for those who suffer from bronchial asthma and healthy ones. The results of the study may be useful in developing educational systems of proactive coping behavior skills for patients with chronic non-specific lung diseases for their health and well-being support.
\end{abstract}

Keywords: coping behavior, coping strategies, proactive coping, patients with chronic non-specific lung diseases.

\section{Introduction}

The problem of one's adaptation in stressful and inconvenient situations generates more interest in foreign and domestic psychology. "Coping behavior is one of the central concepts in psychology of stress and adaptation" (Yaltonskyi, 2010). "Coping behavior - is a type of behavior focused on adaptation to circumstances, which presupposes the ability to use certain means to overcome emotional stress" (Malkina-Pyh, 2005). 
The effectiveness of Coping Strategy depends on personality values and aims, type and phase of stressful event and specific results selected for estimation (Folkman \& Moskowitz, 2004). It was defined that use of one or another coping behavior strategy depends on personality (Bolger, 1990) and type of environment (Mattlin, Wethington, \& Kessler, 1990). There is no universal theory of coping behavior. One of the most popular classifications named after Lazarus R.S., Folkman S. includes problem-focused and emotion-focused coping (Folkman \& Lazarus, 1991; Lazarus, 1991). Problem-focused coping assumes that the efforts are made to improve the "person-environment" relations by changing cognitive evaluation of the situation. Emotional-oriented coping supposes thoughts and actions targeted to reduce physical and psychological stressful influence (Folkman \& Lazarus, 1991; Lazarus, 1991). Lazarus R.S. mentions that although problem-focused and emotions-oriented types of coping are conceptually distinguishable they shouldn't be considered separately, for they are commonly used together (Lazarus, 2000). Coping strategies are determined by cognitive evaluation of the stressor, particularly by rationality and flexibility of judgments and expectation of certain result (Moos \& Schaefer, 1993). Besides coping behavior strategies there are coping recourses. These are personality traits, social or material recourses accessible for an individual to cope with inconveniences (Diener \& Fujita, 1995).

Proactive coping is a special part of the rapidly developing psychological science that studies coping behavior. Proactive coping is a futureoriented (prospective) multidimensional way to overcome difficulties that encompasses the quality of life management and self-control necessary for objective fulfillment (Greenglass, 2002). Proactive coping behavior represents a method of estimating future goals and creating conditions for their successful achievement (Schwarzer \& Taubert, 2002). Aspinwall and Taylor assume that proactive coping is a process that provides preparation for potential future stressors and possibility to prevent them (Aspinwall \& Taylor, 1997).

Proactive coping behavior differs from conventional coping perceptions in three ways (Greenglass, 2002):

1. Conventional coping behavior types are reactive i.e. they deal with stressful events that have already occurred, their purpose is to indemnify the loss or to reduce the harm. Proactive coping is oriented to future. It consists of the efforts directed on creation of general recourses that contribute to fulfilling the tasks and personal growth. 
2. Reactive coping is considered as risk management and proactive coping is the aim of management. While using proactive coping an individual perceives an inconvenient situation as a challenge. One can see the risks, requirements and possibilities associated with one Coping Strategy or another for a problematic situation solving in future, but doesn't see it as a threat, harm or loss. Proactive coping becomes the means for managing the goal instead of managing the risk.

3. Motivation for proactive coping behavior in comparison to conventional coping is more positive, for the situation is perceived as challenge and stimulus, whereas reactive coping comes from the risk estimation, which means requirements are often estimated negatively as threats.

Proactive coping behavior is actively studied in the western countries (Greenglass, 2002; Aspinwall \& Taylor, 1997; Folkman \& Moskowitz, 2004) but remains one of the least discovered phenomena in the field of domestic psychosomatic medicine and psychology, especially for patients with chronic non-specific lung diseases (CNSLD). The purpose of the research is to study the patterns of using proactive coping and adherence to its forms in patients with CNSLD.

\section{Experimental group characteristic and methods}

Study participants $(\mathrm{N}=180)$ were aged 30 to 60 years old. General group included 120 patients suffering from chronic non-specific lung diseases. 7 participants out of the whole experimental group were in-patients of pulmonary department in Moscow Central Clinical Hospital \# 1 OAO "RZhD"; 5 women received treatment in the departments of Moscow Clinical Psychiatric Hospital \# 12 with secondary diagnoses F34.1 and a concurrent organic emotionally labile (asthenic) disorder with vascular genesis; F60.4x histrionic personality disorder, decompensation of brain vascular disease; F06.6 organic emotionally labile (asthenic) disorder. 108 participants were in-patients in Moscow Clinical Hospital \# 70 departments. Sample group of 120 patients was split into two groups. The first one included 60 patients diagnosed with bronchial asthma (BA) (ICD codes J45.0 - J45.9) average age at 47,2 $\pm 10,2$. Females prevailed

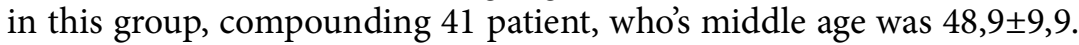
Male patient numbered 19 with average age of $43,4 \pm 10$. Second group also included 60 participants with the diagnosis of chronic obstructive 
pulmonary disease (COPD) (ICD code J44.1), average age 52,7 $\pm 6,1$. On gender sample structure males prevailed (37 patients) with average age of $52,8 \pm 6$. There were 23 female patients with aveage age of $52,6 \pm 6,4$. There was a group of healthy controls $(\mathrm{N}=60)$ who haven't been diagnosed with pulmonary diseases, with average age of $42,8 \pm 8,7$. In this group females prevailed -41 patients with average age of $42,93 \pm 8,9$. Males -19 participants with average age of $42,42 \pm 8,6$. The technique The Proactive Coping Inventory was used to assess the frequency and effectiveness of using Coping Strategies (Aspinwall, Schwarzer, Taubert, 1999, adaptation E. Starchenkova in V. M. Yaltonsky modification, 2009).

\section{Statistical analysis of study results}

While processing the results of the study, arithmetic mean values as well as the standard deviations and reliability of distinctions between groups were calculated. The last indicator was calculated with U-criterion Mann-Whitney test. Computer-based statistical program "Statistica 6.0" and MICROSOFT EXCEL 2003 were used for processing the results. Calculations were made with reliability $\mathrm{p} \leq 0,05$.

\section{Methods' description}

The Proactive Coping Inventory (PCI) was designed by Greenglass, Schwarzer, Aspinwall, Jakubiec, Fiksenbaum, Taubert in 1999. The Inventory evaluates the evidence of one or another coping strategy in individuals. The participant is given the instruction: "The following statements reflect your reactions to different reality situations. Please, leave a mark in the block that coincides with your opinion".

The Inventory consists of 55 statements and includes 6 subscales:

1. The proactive coping subscale.

2. The reflective coping subscale.

3 . The strategic planning subscale.

4. The preventive coping subscale.

5. The instrumental support seeking subscale.

6. The emotional support seeking subscale.

Each statement suggests a certain answer. The answers are estimated in a 4-grade scale: "not at all true" - 1 point, "barely true" - 2 points, "somewhat true" - 3 points, "complete true" - 4 points. The tasks 2, 9, 14 
are reversed items. The scales are interpreted according to the expected value in the study sample.

\section{Study results and their discussion}

The study results revealed that the group of healthy controls and patients with CNSLD tend to use a wide range of proactive coping strategies.

\section{The Proactive Coping Subscale}

Diagram 1 shows that patients with bronchial asthma have demonstrated statistically significant minimum on The Proactive Coping Subscale - 37,7 $\pm 5,5$, in comparison to patients with COPD diagnosis $40,9 \pm 3,6(\mathrm{P}=0,000)$ and healthy controls $-40,7 \pm 6,03(\mathrm{P}=0,002)$. Com-

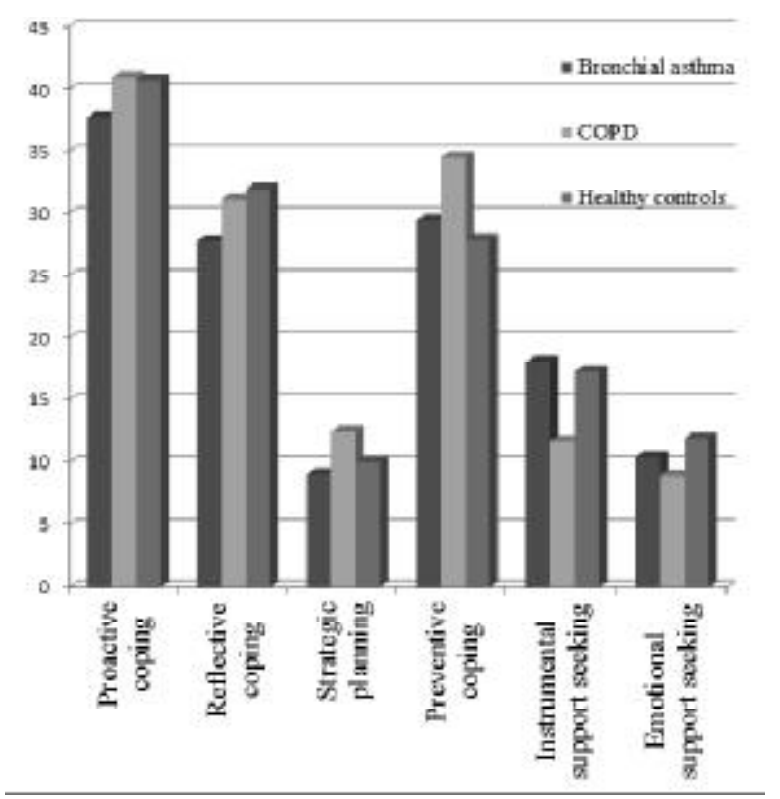

Diagram 1. Average rates of adherence to coping behavior types in patients with bronchial asthma, COPD and healthy controls based on the Proactive Coping Inventory 
parison of another pair of samples between healthy controls and CNSLD patients revealed no significant differences $(\mathrm{P}>0,05)$.

The differences in use of proactive coping between men and women are presented in the table 1 . The definition of objection process is significantly less developed $(\mathrm{P}=0,03)$ in women suffering from bronchial asthma, the average score for this group was $36,85 \pm 6,04$ in comparison to men with bronchial asthma at $39,4 \pm 3,8$. I.e. female patients with bronchial asthma less frequently turn to a capacity that plays an important role in preparation and prevention of potential future stressors than male patients do. COPD patients showed no significant differences $(P>0,05)$ in using proactive coping strategies between male patients who's standard indicators were $41,1 \pm 4,1$. There weren't any significant differences $(\mathrm{P}>0,05)$ in healthy controls regarding use of this type of coping between men who's standard indicators were $-40,9 \pm 6,2$ and women with average score varying within $40,6 \pm 6,02$ ).

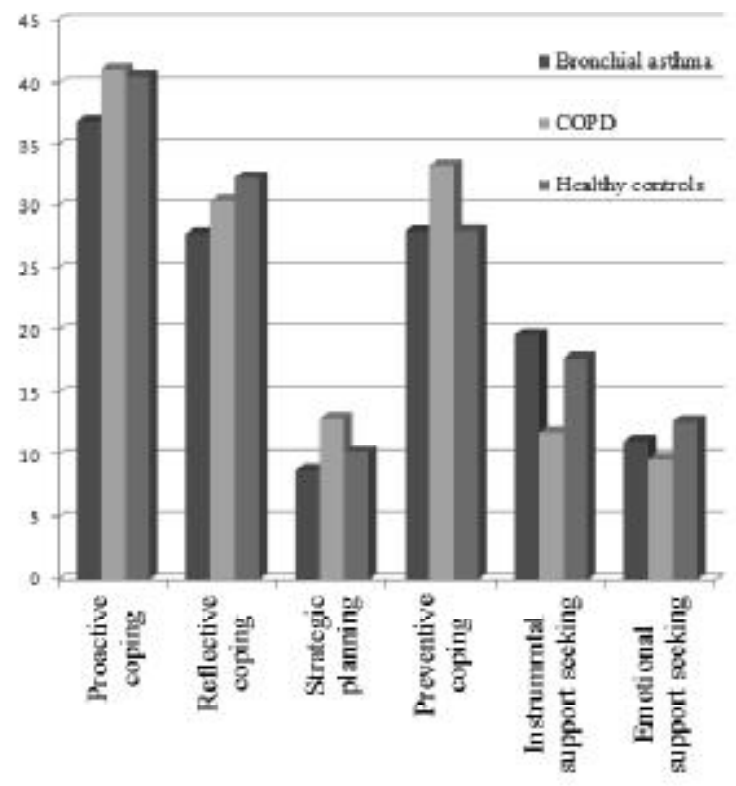

Diagram 2. Average rates of adherence to coping behavior types in female patients with bronchial asthma, COPD and healthy controls based on The Proactive Coping Inventory 
Differences in using proactive coping strategy among male and female patients based on The Proactive Coping Inventory

\begin{tabular}{|c|c|c|c|}
\hline Sample & Male & Female & Reliability \\
\hline Bronchial asthma & $39,4 \pm 3,8$ & $36,85 \pm 6,04$ & $\mathrm{P}=0,03$ \\
\hline COPD & $40,7 \pm 3,2$ & $41,1 \pm 4,1$ & $\mathrm{P}>0,05$ \\
\hline Healthy controls & $40,9 \pm 6,2$ & $40,6 \pm 6,02$ & $\mathrm{P}>0,05$ \\
\hline
\end{tabular}

Comparison of mean values in women in the study groups are shown on diagram 2. Mean values in female healthy controls are significantly higher $(\mathrm{P}=0,002)$ than in female patients with bronchial asthma. Also female patients with COPD have higher scores than women with bronchial asthma $(\mathrm{P}=0,002)$. There were no exact differences in women with COPD and healthy controls considering the use of preventing coping

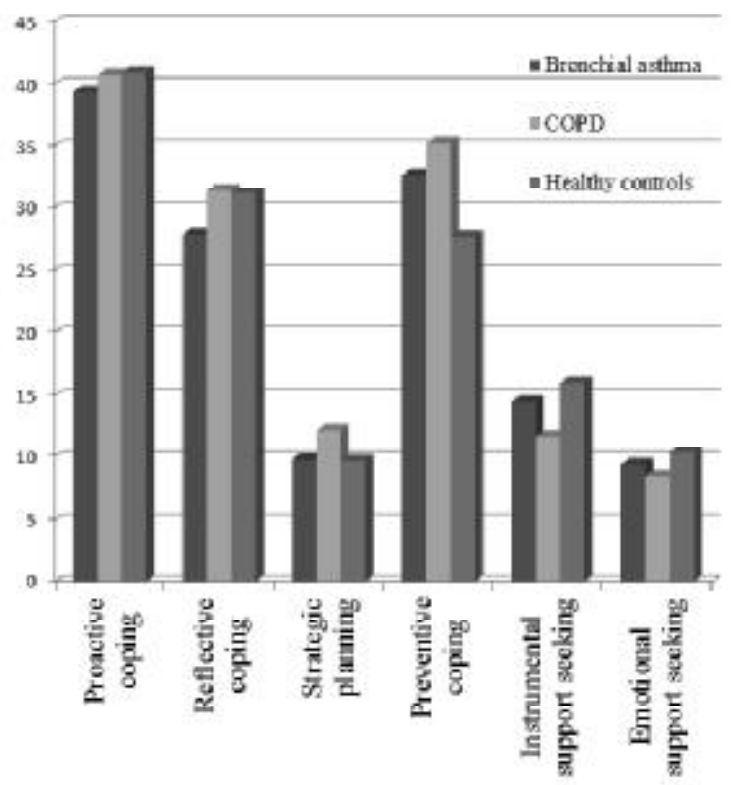

Diagram 3. Average rates of adherence to coping behavior strategy types in male patients with bronchial asthma, COPD and healthy controls based on The Proactive Coping Behavior Inventory 
strategy $(\mathrm{P}>0,05)$. Thus, considering the results given, it is possible to assume that female patients with COPD and healthy controls succeed more in using proactive coping strategy in comparison to bronchial asthma patients.

Comparison of mean values in male participants are shown on diagram 3. There were no significant differences $(P>0,05)$ in use of coping between male patients suffering from CNSLD and male healthy controls. Also there was no significant difference $(P>0,05)$ between bronchial asthma and COPD patients.

Thus, with the results obtained, it is possible to assume that male patients with bronchial asthma set priority targets, and use self-direction in goal achievement more rarely. Healthy controls and COPD patients succeed more at evaluating the priority targets and more actively create conditions for objective fulfillment.

\section{The Reflective Coping Subscale}

The results are presented on diagram 1. Healthy controls demonstrated the highest score on The Reflective Coping Subscale - 32,03 $\pm 6,4$, which indicates that individuals in this group more frequently use this strategy to solve problematic situations than patients with CNSLD. Also significant results were obtained for patients suffering from COPD, who's average score was $31,1 \pm 4,1$. The difference between healthy controls and COPD was insignificant. Reactive coping strategy is underdeveloped among patients with bronchial asthma, as the average score was $27,8 \pm 4,9$, compared to $\operatorname{COPD}(\mathrm{P}=0,000)$ and healthy controls $(\mathrm{P}=0,000)$.

Table 2

Differences in using reflective coping strategy between male and female patients based on the Proactive Coping Inventory

\begin{tabular}{|c|c|c|c|}
\hline Sample & Male & Female & Reliability \\
\hline Bronchial asthma & $27,9 \pm 2,9$ & $27,8 \pm 5,6$ & $\mathrm{P}>0,05$ \\
\hline COPD & $31,5 \pm 4,6$ & $30,4 \pm 2,9$ & $\mathrm{P}>0,05$ \\
\hline Healthy controls & $31,3 \pm 4,9$ & $32,4 \pm 7,03$ & $\mathrm{P}>0,05$ \\
\hline
\end{tabular}

The differences in use of reactive coping between men and women are shown in table 2. Average scores are almost the same in the group of patients with bronchial asthma $-27,9 \pm 2,9$ for men and $27,8 \pm 5,6$ for 
women $(\mathrm{P}>0,05)$. Also there were no significant differences $(\mathrm{P}>0,05)$ in COPD group - average scores were $31,5 \pm 4,6$ for men and $30,4 \pm 2,9$ for women. Average scores for healthy controls were $31,3 \pm 4,9$ (males) and $32,4 \pm 7,03$ (females) $(\mathrm{P}>0,05)$.

Average scores for women in bronchial asthma and COPD groups are shown on diagram 2. Female patients with bronchial asthma apply the reflective coping strategy significantly more rarely in comparison to healthy controls $(\mathrm{P}=0,001)$ and COPD patients $(\mathrm{P}=0,001)$. Comparison of average scores of COPD female patients with healthy controls showed no significant difference $(\mathrm{P}>0,05)$.

Average scores for patients with bronchial asthma, COPD and healthy controls are shown on diagram 3. Men from the healthy controls group more actively use the reflective coping strategy $(\mathrm{P}=0,02)$ than male patients with bronchial asthma. COPD patients as well as the healthy controls $(P>0,05)$ more frequently tend to think their future actions over, plan and try to predict the results in order to cope with problematic situations in comparison to asthmatic patients $(\mathrm{P}=0,000)$.

The obtained results usher an assumption that a more rare use of reflective coping strategy by patients with bronchial asthma may causes poorer presentation of planning and skills, as well as choosing the effective ways of coping with stressful events and thus less successful and prolonged solving of inconvenient situations. The above stated may be a risk of emotional tension and subsequent provocation for an asthmatic attack.

The Strategic Planning subscale

Average scores for all the samples are presented on diagram 1. The COPD patients have the highest score on The Strategic Planning subscale 12,5 $\pm 2,05$ in comparison to patients with bronchial asthma $9,1 \pm 2,1$ $(\mathrm{P}=0,000)$ and healthy controls $10,1 \pm 2,95(\mathrm{P}=0,000)$. Bronchial asthma patients $(\mathrm{P}=0,002)$ use strategic planning significantly more rarely than healthy controls. There was no statistic gender differences between patients suffering from CNSLD and healthy controls revealed $(\mathrm{P}>0,05)$. The differences in using strategic planning in male and female participants are shown in table 3 . Within cells research (diagram 2 ) revealed that female patients with bronchial asthma use coping significantly more rarely than COPD patients $(\mathrm{P}=0,000)$ and healthy controls $(\mathrm{P}=0,01)$. Average scores in females with bronchial asthma were $8,8 \pm 2,2$, for COPD $-12,9 \pm 1,8$ and for healthy controls they were $10,3 \pm 3,1$. Average scores for men in the 
three samples are presented on diagram 3. Men who suffer from COPD are more adherent to planning strategy than asthmatics and healthy controls. For COPD diagnosed men average scores are $12,2 \pm 2,2$ and for healthy controls they are $9,7 \pm 2,65$ which is statistically significant $(P=0,000)$. Significant differences $(\mathrm{P}=0,000)$ are obtained from comparison of $\mathrm{COPD}$ patients and male asthmatics whose average scores were 9,8 $\pm 1,9$.

Table 3

Differences in using strategic planning strategy in male and female patients based on the Proactive Coping Inventory

\begin{tabular}{|c|c|c|c|}
\hline Sample & Male & Female & Reliability \\
\hline Bronchial asthma & $9,8 \pm 1,9$ & $8,8 \pm 2,2$ & $\mathrm{P}>0,05$ \\
\hline COPD & $12,2 \pm 2,2$ & $12,9 \pm 1,8$ & $\mathrm{P}>0,05$ \\
\hline Healthy controls & $9,7 \pm 2,65$ & $10,3 \pm 3,1$ & $\mathrm{P}>0,05$ \\
\hline
\end{tabular}

Based on the record the following conclusions can be made. Patients with bronchial asthma significantly tend to use strategic planning more rarely than COPD patients and healthy controls. This may cause disorganization of their activity in solving problematic situations. COPD patients use rational methods more frequently - they split the goal achievement process into stages while solving inconveniences, unlike patients of other groups.

The Preventive Coping Subscale

The data is presented on diagram 1. COPD patients demonstrated higher scores on The Preventive Coping Subscale 34,5 $\pm 3,8$ than healthy controls $27,9 \pm 5,6(\mathrm{P}=0,000)$ or bronchial asthma patients $29,45 \pm 4,75$ $(\mathrm{P}=0,000)$.

Within-cells research (table 4) showed significant differences in average scores for using the strategy between men and women suffering from CNSLD. For COPD male patients average scores vary within $35,2 \pm 4,2$ while for females they are $33,35 \pm 2,8(\mathrm{P}=0,000)$. Male patients with bronchial asthma had significantly $(\mathrm{P}=0,000)$ higher scores $32,7 \pm 2,6$, than females with the same diagnosis $-28 \pm 4,8$. Thus males with CNSLD use preventive coping strategy more often. No significant gender differences were revealed in healthy controls $(\mathrm{P}>0,05)$. Average scores for healthy men were $27,7 \pm 5,4$ and for women they were $28,05 \pm 5,7$. 
Differences in use of preventive coping strategy in male and female patients based on the Proactive Coping Inventory

\begin{tabular}{|c|c|c|c|}
\hline Sample & Male & Female & Reliability \\
\hline Bronchial asthma & $32,7 \pm 2,6$ & $28 \pm 4,8$ & $\mathrm{P}=0,000$ \\
\hline COPD & $35,2 \pm 4,2$ & $33,35 \pm 2,8$ & $\mathrm{P}=0,000$ \\
\hline Healthy controls & $27,7 \pm 5,4$ & $28,05 \pm 5,7$ & $\mathrm{P}>0,05$ \\
\hline
\end{tabular}

As it is shown on diagram 2, female patients with COPD use preventive coping strategy significantly more often than bronchial asthma patients $(\mathrm{P}=0,000)$ and healthy controls $(\mathrm{P}=0,000)$. No significant differences $(\mathrm{P}>0,05)$ in use of coping strategy was revealed between female patients with bronchial asthma and healthy controls. Average scores for male participants of all groups are presented on diagram 3. COPD male patients use this strategy significantly more frequently than healthy controls $(\mathrm{P}=0,000)$ and asthmatic males $(\mathrm{P}=0,000)$. Men suffering from bronchial asthma use $(\mathrm{P}=0,005)$ preventive coping significantly more often than healthy controls do.

Considering the above mentioned it is possible to assume that COPD patients in comparison to asthmatics and healthy controls are more responsible in arranging their actions directed to maintaining their health and well-being such as saving money, timely taking medication and regular examinations in order to prevent functional recrudescence.

The Instrumental Support Seeking Subscale

As it is seen on diagram 1, COPD patients have the least scores $11,75 \pm 2,2$ compared to patients suffering from bronchial asthma $-18,1$ $\pm 4,1(\mathrm{P}=0,000)$ and healthy controls $-17,3 \pm 5,1(\mathrm{P}=0,000)$. After inter comparison of healthy controls and asthmatic patients the value wasn't significant $(\mathrm{P}>0,05)$.

Within-cells differences between males and females are demonstrated in table \#5. In COPD patients there was no significant gender differences considering the use of instrumental support seeking strategy $(\mathrm{P}>0,05)$. The average score in the COPD group for females was $11,8 \pm 2,6$ and for males it was $11,7 \pm 2$. There was no significant gender difference in healthy controls group $(\mathrm{P}>0,05)$. The scores varied within a range of 
$17,85 \pm 5,25$ for women and $16 \pm 4,5$ for men. Asthmatic female patients than male asthmatics significantly more often $(\mathrm{P}=0,000)$ ask for advice and retrieve information from other people to use it in solving problematic situations.

Table 5

Differences in using instrumental support seeking strategy in male and female patients based on the Proactive Coping Inventory

\begin{tabular}{|c|c|c|c|}
\hline Sample & Male & Female & Reliability \\
\hline Bronchial asthma & $14,5 \pm 1,7$ & $19,7 \pm 3,85$ & $\mathrm{P}=0,000$ \\
\hline COPD & $11,7 \pm 2$ & $11,8 \pm 2,6$ & $\mathrm{P}>0,05$ \\
\hline Healthy controls & $16 \pm 4,5$ & $17,85 \pm 5,25$ & $\mathrm{P}>0,05$ \\
\hline
\end{tabular}

On diagram 2 it is shown that females with bronchial asthma use instrumental support seeking strategy significantly more often than healthy controls $(\mathrm{P}=0,02)$ and COPD patients $(\mathrm{P}=0,000)$. Thus women with bronchial asthma have a greater need in retrieving the information from other people to solve problems than COPD patients and controls. In their turn, females with COPD use this type of coping significantly more rarely $(\mathrm{P}=0,000)$.

As it is shown on diagram 3 male participants from healthy controls use instrumental support significantly more often than COPD male patients $(\mathrm{P}=0,001)$. No difference was revealed between asthmatic male patients and healthy controls $(\mathrm{P}>0,05)$ considering this type of coping. COPD patients use this kind of coping strategy significantly more rarely than asthmatics $(\mathrm{P}=0,000)$.

In accordance with the study results, an assumption can be made: an underdeveloped instrumental support seeking strategy in COPD patients may narrow patient's horizons in problem-solving and stress-management and limit toping ability. Providing awareness of instrumental support seeking coping strategy for somatic patients may create a perception of successful problem managing. Knowing that these resources are available should level down the subjective threat caused by stressful situations.

The Emotional Support Seeking Subscale

The lowest scores on emotional support seeking strategy was demonstrated in COPD patients - with average indicators ranges at $8,98 \pm 2,5$. It's 
significantly less than bronchial asthma group $(\mathrm{P}=0,000)$, which scored $10,5 \pm 1,9$ and healthy controls $-(\mathrm{P}=0,000)-11,98 \pm 3,7$ (diagram 1$)$. The differences between patients with bronchial asthma and controls are insignificant $(\mathrm{P}>0,05)$.

Gender associated differences in using emotional support seeking strategy in all patient groups are demonstrated in table 6 . Women with bronchial asthma use the emotional support seeking strategy significantly more often $(\mathrm{P}=0,003)$ than men with the same diagnosis. Average scores in female patients with bronchial asthma are $11,1 \pm 1,8$ and $9,4 \pm 1,8$ for males with the same diagnosis. Healthy control females are also more often to use the emotional support seeking strategy $(\mathrm{P}=0,04)$, with their average scores being at $12,7 \pm 3,5$, meanwhile male controls scores are $10,4 \pm 3,7$. Thus it is reasonable to assume that healthy controls and astigmatic patients are in a greater need of safe emotional atmosphere, trustful and supportive relations with closest environment. There were no significant gender differences in COPD patients $(P>0,05)$. Average scores for male COPD patients were at $8,5 \pm 1,8$ and for females - at $9,7 \pm 3,2$.

Table 6

Differences in using of emotional support seeking strategy in male and female patients based on the Proactive Coping Inventory

\begin{tabular}{|c|c|c|c|}
\hline Sample & Male & Female & Reliability \\
\hline Bronchial asthma & $9,4 \pm 1,8$ & $11,1 \pm 1,8$ & $\mathrm{P}=0,003$ \\
\hline COPD & $8,5 \pm 1,8$ & $9,7 \pm 3,2$ & $\mathrm{P}>0,05$ \\
\hline Healthy controls & $10,4 \pm 3,7$ & $12,7 \pm 3,5$ & $\mathrm{P}=0,04$ \\
\hline
\end{tabular}

COPD patients use emotional support seeking strategy significantly more rarely than healthy controls $(\mathrm{P}=0,001)$ and female patients with bronchial asthma $(\mathrm{P}=0,001)$ (diagram 2$)$. There was no significant difference in the use of emotional support seeking strategy between healthy control females and women suffering from bronchial asthma $(\mathrm{P}>0,05)$.

There haven't been any significant differences found $(P>0,05)$ in male participants using emotional support seeking strategy between bronchial asthma, COPD and control groups (diagram 3 ). Healthy controls used this type of coping significantly more often $(\mathrm{P}=0,04)$ than COPD patients. 
In conclusion it is reasonable to presume that COPD patients are less satisfied with the emotional support that they receive from their relatives and closest environment, it's harder for them to reveal their feelings and emotions than it is for patients suffering from bronchial asthma and healthy controls.

\section{Conclusion.}

1. Patients with chronic non-specific lung diseases use different types of proactive coping behavior while solving problematic and stressful situations.

2. Patients with bronchial asthma are insufficient to develop skills of independent decision making, definition of objectives, considerate options in solving conflicts and other inconvenient situations.

3 . Females suffering from bronchial asthma rarely tend to use proactive coping strategies, they also feel greater need to retrieve information from social environment in order to solve problems in comparison to male patients with the same diagnosis.

4. Bronchial asthma patients use strategic planning strategy more rarely than COPD patients and healthy controls which possibly may prevent them from solving inconvenient and stressful situations.

5. COPD group and healthy controls succeed in evaluating their goals and actively creating conditions for more effective fulfillment of their objectives.

6. Male COPD patients and healthy controls have a better developed ability to define the goals, think over the different possibilities of problem solving and predict the outcomes in order to deal with difficult situations.

7. Men suffering from CNSLD have a tendency to use preventive coping strategy more actively than women with the same diagnosis.

8. Male COPD patients are more responsible in arranging their actions directed to maintaining their health and well-being such as saving money, timely taking medication and going through regular examinations in order to prevent one or another functional recrudescence.

9. Underdeveloped instrumental support seeking strategy in patients with COPD may cause limitations of means of solving difficult and stressful situations and thus to higher risks of disadaptation reactions in inconvenient atmosphere. 
10. Healthy controls and patients with bronchial asthma feel greater need and satisfaction in a safe emotional atmosphere, trustful and supportive relationships with social environment.

11. Patients with chronic obstructive pulmonary disease are less satisfied with the emotional support that they receive from their relatives and closest environment, its harder for them to reveal their feelings and emotions than it is for patients who suffer from bronchial asthma and healthy controls.

\section{Summary}

CNSLD is one of the most difficult and significant problems in modern pulmonology. The importance of preventive measures in patients with CNSLD is caused by its polyethiology and pathogenetic complexity, high prevalence rate, absence of radical treatment, understudies in development aspects of COPD and bronchial asthma and also by poor patients' awareness about the ways of sustaining their health and well-being not only by means of pharmacotherapy, but also using psychological methods. The abovementioned makes this problem rather urgent for further development, stating the need to research new ways of pharmacotherapy and methods to support poor health. Prevention of CNSLD should include a complex of measures such as elimination of health risks that may cause exacerbation, relapse or progression of the disease. The most common psychological risk factors are inability to predict and solve reality difficulties and stressors and to respond to these situations adequately. In conclusion it appears reasonable to use maintained patients' awareness of various types of proactive coping behavior in order to support their health. The ability to accurately use different types of proactive coping behavior should teach the patient to be more conscious and responsible when taking actions aimed at maintenance of health and well-being such as saving money, taking treatment on schedule, going through medical examinations regularly, also set the goals, split actions into stages, do planning and masterminding and learn to predict the results of each action. Thus boosting individual's tolerance to stress will raise the effectiveness of prevention of exacerbation and relapse of the disease. 


\section{References}

Aspinwall, L.G, \& Taylor, S.E. (1997). A stitch in time: Self-regulation and proactive coping. Psychological Bulletin, 121(3), 417-436.

Bolger, N. (1990). Coping as a personality process: A prospective study. Journal of Personality and Social Psychology, 59, 525-537.

Diener, E., \& Fujita, F. (1995). Resources, personal strivings, and subjective wellbeing: a nomothetic and idiographic approach. Journal of Personality and Social Psychology, 68, 926-935.

Folkman, S., \& Lazarus, R.S. (1991). Coping and emotion. In A. Monat, \& R.S. Lazarus, Stress and Coping (pp. 207-227). New York.

Folkman, S., \& Moskowitz, J.T. (2004). Coping: Pitfalls and promise. Annual Review of Psychology, 55, 745-774.

Greenglass, E. (2002). Chapter 3: Proactive coping and quality of life management. In E. Frydenberg (Ed.), Beyond coping: Meeting goals, vision, and challenges (pp. 37-62). London: Oxford University Press.

Lazarus, R.S. (2000). Toward better research on stress and coping. American Psychologist, 55, 665-673.

Lazarus, R.S., \& Folkman S. (1991). The concept of coping. In A. Monat, \& R.S. Lazarus, Stress and Coping (pp. 189-206). New York.

Malkina-Pyh, I.G. (2005). Koping strategii pri stresse [Coping strategies in stress]. Moskovskij psikhologicheskij zhurnal, 12. Internet recourse URL: http://magazine. mospsy.ru/nomer12/s11.shtml

Mattlin, J., Wethington, E., \& Kessler, R.Cl. (1990). Situational determinants of coping and coping effectiveness. Journal of Health and Social Behavior, 31. 103-122.

Moos, R., \& Schaefer, J.A. (1993). Coping Resources and Processes: Current Concepts and measures. In L. Goldberg, \& S. Breznitz (Eds.), Handbook of Stress: Theoretical and Clinical aspects, 2nd ed. (Chapter 13: pp. 234-258). New York: Free Press.

Schwarzer, R., \& Taubert, S. (2002). Tenacious goal pursuits and striving toward personal growth: Proactive coping. In E. Fydenberg (Ed.), Beyond Coping: Meeting Goals, Visions and Challenges (pp. 19-35). London: Oxford University Press.

Yaltonskyi, V.M. (2010). Sovremennye teoreticheskie podhody k issledovaniju sovladajuschego povedenija [Modern theoretical concepts in research of coping behavior] (Internet recourse). Medicinskaja psikhologija v Rossii: jelektronnyj nauchnyj zhurnal, 1. URL: http:// www.medpsy.ru/mprj/archiv_global/2010_1_2/nomer/nomer03.php $(19.10 .2010)$ 